\title{
CAMPESINATO, ENSINO DE GEOGRAFIA E ESCOLAS DO CAMPO: O CONHECIMENTO GEOGRÁFICO COMO UM SABER EM CONJUNTO1
}

\author{
Alexandra Maria Oliveira*
}

\begin{abstract}
Resumo
Esta pesquisa tem como objetivo apresentar uma leitura sobre a contribuição da Geografia, como disciplina escolar, na leitura da realidade no semiárido. Aborda-se no texto um momento de socialização de professores e alunos na escola do Assentamento 25 de Maio, Madalena, Ceará. No diálogo, a escola foi vista como lugar de construção de conhecimentos em conjunto com aprendizagens significativas, e a Geografia como disciplina fundamental na compreensão das relações sociais do semiárido. Sua inserção na escola do campo tem acontecido no caminho da proposta dos movimentos camponeses na construção da política educacional para o campo. Essas são interpretações relevantes na compreensão da realidade que envolve a geografia escolar e a escola do campo, que se encontram no processo de espacialização da luta camponesa no Brasil.
\end{abstract}

Palavras chave: campesinato, escola do campo; ensino de Geografia.

Peasantry, Geography teaching and the country schools: the geographical knowledge as group knowledge.

\begin{abstract}
The aim of this research is to present a lecture on the contribution of geography as a school discipline, about reading the reality of the semiarid. The text approaches a moment of socialization of teachers and students in a school in the settlement 25 de Maio in the discrict of Madalena, state of Ceará. In the dialogue, the school was seen as a place to construct knowledge together with significant learning, and geography as a core discipline in understanding the social relations of the semiarid. Its inclusion in the school has happened in the way of the proposal of peasant movements in the construction of educational policy for the country people. These interpretations are relevant to understand the reality that surrounds the school geography and the country school which are in process of spatialization of peasant struggle in Brazil.
\end{abstract}

Keywords: peasantry; country school; Geography teaching

\section{Introdução}

Discutir reforma agrária, campesinato, movimentos sociais, ensino de geografia e educação do campo desafia-nos a refletir sobre a pertinência da Geografia como disciplina escolar nas escolas do Ceará, bem como sua importância na formação dos professores e no entendimento das questões que perpassam 
a vida no semiárido. A coleta de dados desta pesquisa incluiu visitas de reconhecimento, entrevistas com educadores e educandos sobre suas práticas, anotações de campo, reuniões de preparação de atividades em conjunto e desenvolvimento de oficina didática. Abrangeu, ainda, pesquisa documental em livros, teses, relatórios, documentos oficiais e seminários de estudo sobre educação do campo, entre outras atividades.

A Geografia, como disciplina escolar, tem papel relevante no entendimento dos processos que envolvem a relação campesinato, ensino de geografia e reforma agrária; a pesquisa com extensão tem possibilitado um reconhecimento de nossa prática docente no trabalho com a disciplina no mundo da escola. A escola do campo é vista como uma proposta que nasceu de demandas dos movimentos camponeses na construção de uma política educacional para os acampamentos e assentamentos de reforma agrária. Essa interpretação é relevante na compreensão da realidade que envolve a escola do campo, que se encontra no processo de espacialização da luta camponesa.

No primeiro momento, enfoca-se a política de educação desenvolvida no campo e a distinção entre educação no campo e educação do campo. Em seguida, reporta-se à discussão da Geografia agrária sobre a questão da propriedade privada da terra e sobre a importância dos movimentos sociais na conquista de frações do território que estão sendo apropriadas pelos camponeses na luta pela terra, e, por fim, apresenta-se o trabalho realizado em conjunto com professores das escolas do assentamento 25 de maio, localizado no município de Madalena, Ceará. Nesse contexto, a educação do campo, defendida pelos movimentos e representações camponesas, é parte constitutiva para o seu desenvolvimento. Portanto, pretende-se com este relatório contribuir para a discussão acadêmica, e quiçá para os movimentos sociais, no âmbito da geografia agrária e do ensino de geografia, enfocando os desafios colocados para a formação dos professores de Geografia e a luta pela terra no campo cearense.

\section{A política de educação desenvolvida no campo}

A concepção de educação levantada na Lei de Diretrizes e Bases da Educação Brasileira (LDB, 1996), tem sido com frequência apresentada a partir de um paradigma urbano-industrial. Nas expressões que vinculam a educação escolar à cidadania e ao mundo do trabalho, a cidade aparece como o espaço por excelência do convívio social. A essa idealização da cidade como o lugar do moderno, do dinâmico e da produção corresponde uma visão negativa do campo como lugar do atraso, do descanso, da resistência e do não produtivo. É uma leitura proposta que vai ao encontro da inviabilidade da reforma agrária e do fortalecimento do agronegócio, tendo por base o paradigma do capitalismo agrário proposto por intelectuais como Abramovay (1992) e Silva (2001). Essas imagens que se complementam sugerem políticas públicas, educativas e escolares e, ainda, inspiram a maior parte dos textos legais que legislam nosso sistema educativo e a formação de professores.

A rigor, o campo e a diversidade de seu povo não foram esquecidos na LDB (1996). As diretrizes operacionais para as escolas do campo visam adequar o projeto institucional das escolas do campo aos currículos nacionais. A recomendação básica é não esquecer "a diversidade", adaptando as condições do campo à educação escolar, ao currículo comum e à formação dos professores, sob a perspectiva urbano-industrial.

Fernandes e Molina (2004), ao refletirem sobre a área da educação do campo, elaboram esquema em que distinguem o campo do agronegócio do campo da agricultura camponesa, identificando o paradigma da educação rural com o primeiro e o da educação do campo com o segundo. Portanto, desenvolve-se uma educação do campo cujo foco não está apenas no campo em si; tem projeto político pedagógico articulado com um plano de desenvolvimento de vida e formação a favor dos pobres do campo.

A diferenciação entre a educação do campo com a tradicional educação rural, conforme afirmou Carvalho (2006), não é só de projeto político, mas de diversos fatores. Pode-se destacar a metodologia referenciada 
na educação popular e, portanto, voltada para a realidade dos educandos, organizando-se em tempo-escola e tempo-comunidade, e a proposta político-pedagógica voltada para temas relativos à vida, às lutas e a um projeto de desenvolvimento sustentável para o Brasil.

Por conseguinte, as diferenças estão postas no desafio da formação dos sujeitos sociais que estão na luta pela construção teórica e prática dos projetos. As políticas de formação dos professores descritas na legislação brasileira não estão dando conta do movimento da sociedade.

Arroyo (2007), ao analisar políticas de formação de educadores(as) do campo, revelou que as consequências da inspiração no paradigma urbano são marcantes na secundarização do campo e na falta de políticas para o campo em todas as áreas públicas, especialmente na saúde e na educação. O campo é visto como um lugar constituído por grupos sociais atrasados que, no processo de integração ao mundo do mercado, passarão pela transformação de camponeses para agricultores familiares.

Nessa leitura paradigmática - que é hegemônica na realidade brasileira - a reforma agrária, os serviços públicos e as políticas públicas para a formação específica de educadores(as) do campo não fazem sentido. Como consequência, o quadro que se nos apresenta é de profissionais que se deslocam cotidianamente para a escola viajando por horas em estradas de terra para trabalhar nas precárias e distantes comunidades rurais. Paralelamente, os alunos jovens do campo são alocados em salas de aula deterioradas ou improvisadas e, ainda, deslocados para a escola da cidade, para estudar com professores e colegas citadinos. Trata-se de uma política que expressa desrespeito às raízes, aos valores e às crenças culturais e inviabiliza o acesso à escola na comunidade.

O interessante para essa análise é que a desarticulação da escola para as comunidades rurais - que se desdobra na insatisfação dos professores(as) com as condições de trabalho; uso de salas de aula improvisadas, uso transporte escolar sem segurança, saída dos alunos para as escolas da cidade, entre outros pontos -, esteja acontecendo em tempos de reafirmação do campo, um processo que vem se estabilizando há mais de vinte anos através da presença política dos camponeses organizados em movimentos sociais. Nunca o campo brasileiro esteve tão dinâmico na luta por direitos ao mostrar sua identidade, cultura, seus valores e sua organização política, tendo como principais representações no Ceará a Comissão Pastoral da Terra (CPT) e o Movimento dos Trabalhadores Rurais Sem Terra (MST).

De acordo com Seoane(2003) os semterra no Brasil e os zapatistas no México estão entre os quatro mais importantes movimentos sociais da América Latina.

(...) los movimientos sociales de origen rural más importantes en la última década en Latinoamérica: el Movimiento de los Trabajadores Sin Tierra (MST) en Brasil, el movimiento cocalero del Chapare boliviano, la experiencia de la Confederación de Nacionalidades Indígenas del Ecuador, y el zapatismo en México (Seoane,2003:13).

A consolidação desses movimentos sociais passa por princípios, organicidade e ações que são recriadas e apresentadas com uma nova configuração sob forma de protestos e debates sobre as alternativas a serem adotadas em favor do povo do campo. A presença marcante dos sem-terra em rede nacional e internacional não apenas reivindicando ser beneficiários de direitos, mas também ser sujeitos, agentes históricos da construção dos seus direitos incomoda a elite brasileira.

Nesse sentido, a questão que surge é: qual o sentido da não realização de uma política específica para a formação de uma educação do campo voltada para um projeto de valorização do povo do campo? A falta de políticas específicas de formação de educadores(as) e a desarticulação das escolas rurais fazem parte de uma estratégia de desestruturação dos movimentos sociais do campo e de fortalecimento de um projeto de educação afinado entre governo, banco mundial e elite brasileira.

$\mathrm{Na}$ luta por um projeto popular de desenvolvimento do campo, os sem-terra expressam a concepção do direito à educação e do dever do 
Estado. No processo de construção da realidade, novas categorias emergem no mundo da escola. Conceitos como educação do campo, pedagogia do movimento, escola do campo, nasceram de demandas dos movimentos camponeses na construção de uma política educacional para os acampamentos e assentamentos de reforma agrária do MST.

No processo de luta pela reforma agrária, a posse da terra passa a ser condição para se viabilizar um conjunto de outras lutas, entre outras, a mobilização de forças por estrutura viária básica, por escolas e formação de qualidade, pelo acesso à universidade, por educação contextualizada. Esse é um fato extremamente relevante na compreensão dos processos políticos e sociais que envolvem a escola do campo. De acordo com Fernandes (2006), foi da demanda específica por educação nos acampamentos e assentamentos do MST que nasceu em 1998 o Programa Nacional de Educação na Reforma Agrária (Pronera), vinculado ao Ministério de Desenvolvimento Agrário, e a Coordenação Geral de Educação do Campo.

Carvalho (2006), ao analisar o Pronera no Ceará, reafirmou o fato de os movimentos sociais do campo na luta pela garantia do direito à educação passarem a reivindicar de forma expressiva, a partir de meados da década de 1990, junto ao governo federal, uma política educacional pública que viesse a atender as necessidades da classe trabalhadora rural.

Nesse contexto, a educação do campo deve ser compreendida como um processo em construção que contempla, em sua lógica, a política que pensa a educação proposta pelos sem-terra como parte constitutiva e essencial para o desenvolvimento do campo a partir de projeto popular.

A leitura midiática sobre ensino, juventude e educação no Brasil está sempre amarrada aos baixos índices de rendimento, e às altas taxas de analfabetismo e de evasão escolar e a problemas relacionados ora a questões sociais como a fome e a miséria, ora a questões econômicas como a falta de emprego entre os jovens.

Entretanto, para Martins (2008), as notícias sobre o ensino e a educação no Brasil nem sempre tocam no essencial. As preocupantes adversidades pouco tratam do fato de que há no País um generalizado apreço pela vontade de aprender, embora muitas vezes em lugares de absoluta ausência do poder público. Muito do que existe de valorização da escola rural é, sem dúvida, devido em grande parte ao êxito da escolarização promovida pelo MST. Apesar dos conteúdos pedagógicos discutíveis e dos simplismos ideológicos, no particular da escola rural, o Movimento tem suprido carências de saber com criatividade e conservado a utopia da universalidade do ser e do direito. Isso acontece, sobretudo, porque a ideologia educativa do MST tem a coerência que falta à ideologia sindicalista dos professores da rede pública e privada de ensino: a escola dos sem-terra liga-se ao projeto utópico de um modo de vida viável e representativa de uma resistência legítima às diferentes forças que, em nome da grande economia multinacionalizada e voraz, nulificam valores, crenças, maneiras de viver e capitais sociais acumulados ao longo dos séculos.

No semiárido cearense, essa disposição para aprender foi algo visto no rosto de crianças e jovens caminhando com cadernos nas mãos, debaixo de sol ou de chuva, em direção à escola; na presença maciça dos alunos nas escolas e no esforço contínuo de professores(as) para levar algo novo para a sala de aula. Na escola do Assentamento 25 de maio, a gestão escolar é feita por um coletivo do setor de educação do MST formado por professores(as), alunos(as) e comunidade, que diariamente discutem ações no sentido de fortalecer a luta por um ambiente escolar com professores(as) qualificados em cursos de nível superior, por condições dignas de trabalho docente, escolas com espaços de estudo, jardins, hortas, quadra de esporte, quadro em boas condições de uso, salas amplas e arejadas; pelo acesso a material pedagógico, à leitura e ao livro, ao aprendizado, a saberes alternativos, às formas de cultura e de compreensão do mundo. Na comunidade, a escola é a extensão da casa e a educação uma herança que tem sido cultivada 
pela família. No parentesco escolar, a professora é sobrinha da cozinheira, e as cozinheiras, por sua vez, são tias e madrinhas dos alunos. Ali, antes da aula um ou outro aluno aparece na porta da sala dando notícias da parentalha e pedindo a bênção, sendo logo abençoado.

Nessa escola, o professor é tratado com admiração e respeito por ter clareza de sua função social e o conhecimento como um saber construído, por princípio, no conjunto. E a escola é um espaço de fortalecimento de um projeto popular de desenvolvimento do campo. Nesse momento, o ensino passa a ser contextualizado, como podemos observar na fala a seguir:Relacionar a vivência do aluno com a educação formal [vista no livro didático] é uma coisa que eu acho interessante. Por exemplo, eu não descarto o livro didático porque se eu pegar uma história ou um texto que eu possa relacionar com a vivência do aluno, esse texto é bem aceito. Isso não significa que eu estou trabalhando só o livro didático, mas eu estou associando a realidade do aluno com outra visão. Alguns alunos até perguntam: Tia, por que é que eu vou estudar sobre trânsito, meio de transporte, leis, se aqui eu vivo no mato? Então respondo: olha pessoal é porque nós precisamos nos inteirar de todos os conhecimentos, não é porque nós vivemos aqui na zona rural que não precisamos saber o que é lei de trânsito. Por isso é que acontecem acidentes nas estradas que a gente vai; porque ninguém sabe o que é lei de trânsito. Se você vai participar de um encontro, de uma manifestação, de uma marcha na cidade, como é que você vai fazer para se orientar na cidade, se não estudar a lei de trânsito? Você sendo do interior, mesmo estando na escola, vai se sentir analfabeto, porque não vai saber se orientar nas leis e direções e nos fluxos de carros e pedestres. Você não vai estudar só o que é da cidade ou só o que é do interior, você tem que fazer a relação como um todo (Professora, Assentamento 25 de Maio, 2008).

O questionamento do aluno revelou uma inquietação na procura de esclarecimento sobre um assunto abordado que parecia descontextualizado e a resposta da professora contextualizou o assunto corporificando-o num exemplo de uma concepção de ensino essencialmente freiriana. Para Freire (2006), a educação é entendida como um ato de intervenção intencional no qual o sujeito, consciente de sua ação, deve agir com o seu conhecimento no sentido da transformação.

Arroyo (2007), ao analisar a tradição de políticas educacionais generalistas no Brasil, reconheceu a importância dos novos sujeitos sociais na construção de um movimento pedagógico construído a partir dos camponeses. Assim, a valorização da escola do campo é, sem dúvida, um êxito da escolarização promovida pelo MST, mas isso não tem significado avanços no reconhecimento das especificidades de políticas para a diversidade de coletivos que fazem parte de nossa formação social e cultural.

A generalização dos direitos sem o reconhecimento das diferenças tem como desdobramento as tensões. Nesse quadro e parafraseando Oliveira (2001), não há como pensar que a reforma agrária, ou a educação do campo, será feita de maneira pacífica no País.

\section{escolas do campo}

\section{Geografia, questão agrária e}

A Geografia brasileira tem em sua sistematização um vasto campo teórico pautado na discussão sobre a história, a origem e os processos que compõem a formação territorial brasileira. 0 paradigma da questão agrária trouxe influências teóricas e práticas para se estudar o movimento desigual, contraditório e combinado do território brasileiro e suas transformações recentes. Nessa construção, o território tem sido um conceito chave que se apresenta no centro da discussão.

$\mathrm{Na}$ Geografia agrária, o estudo do território como categoria primordial de investigação tem sido fundamentado em livros, teses e dissertações de autores como Raffestin (1993), Oliveira (1999) e Fernandes (2006). Para Oliveira (1999), o território deve ser entendido como síntese contraditória da espacialidade que a sociedade tem e desenvolve. Logo, a construção do território é contraditoriamente o desenvolvimento desigual, simultâneo e combinado. O território é, 
assim, produto concreto da luta de classes travada pela sociedade no processo de produção de sua existência; sociedade capitalista, assentada em conflituosas relações entre diferentes classes sociais fundamentais.

Nessa leitura, a análise sobre a compreensão das transformações territoriais recentes no campo brasileiro considera que as relações sociais são partes constitutivas de territórios ou dimensões territoriais, e, ainda, que os territórios são espaços geográficos e políticos onde os sujeitos sociais discutem, planejam e constroem seus projetos de vida e de lutas sociais. No processo, os sujeitos sociais organizam-se por meios de relações de classe para desenvolver seus campos de lutas. Nesse contexto, Fernandes (2006) acrescentou o fato de que a educação proposta pelos movimentos camponeses não existe fora do território, assim como não existem a cultura, a economia e outras dimensões mais. Assim, esse autor trouxe para a Geografia a importância de se compreender a dimensão educativa contida nos processos de espacialização e territorialização da luta pela terra no Brasil.

De acordo com Oliveira (1999), a formação territorial capitalista no campo brasileiro está marcada pelos processos de territorialização do capital e de monopolização do território pelo capital. Esse fenômeno encontra-se, ainda, contraditoriamente marcado pelo processo de expansão da agricultura camponesa, que tem nas ocupações, nos acampamentos e nos assentamentos rurais ações efetivas de resistência e luta pela reforma agrária.

O movimento de luta nos últimos anos desenvolveu diferentes dimensões sociais, políticas e econômicas, e ganhou diferentes dimensões territoriais no País. No Ceará, a conquista de frações do território capitalista que estão sendo apropriadas pelos camponeses na luta pela terra tem contribuído para o fortalecimento de dimensões como a educativa, que perpassa a social, a econômica e a política. Oliveira (2008), ao analisar os saberes e as práticas presentes na unidade camponesa nos sertões cearenses, descreveu o processo de constituição da vida de assentado, no qual a terra camponesa se revela como uma fração do território capitalista apropriada pelos camponeses. Os assentamentos rurais têm desenvolvido diferentes leituras de construção da realidade social para o povo pobre do campo. Nesse contexto, os assentamentos rurais tornam-se um recurso poderoso na espacialização da luta camponesa, que vai desenvolvendo no território conquistado o sentido de trunfo proposto por Raffestin (1993), ao defender esse sentido como um poderoso conceito do campo geográfico.

A análise sobre a reprodução do campesinato e a luta pela educação do campo no seio da sociedade capitalista perpassa a leitura da realidade presente no projeto popular defendido pelos movimentos sociais e pelas representações camponesas que atende as necessidades básicas do povo do campo, algo inconciliável com o projeto oficial. E é por meio dessa lógica contraditória que procuramos entender as práticas sociais e educativas presentes nos assentamentos rurais organizados pelo MST no Ceará.

A construção recente de uma leitura sobre o campesinato brasileiro e a luta por uma educação que contemple os saberes, as práticas e as experiências no campo têm sido desenvolvidas por Stedile e Fernandes (1999), Arroyo e Fernandes (1999), Caldart (2000) e Arroyo (2007), entre outros autores. A manutenção de diferentes formas de produção e trabalho na terra camponesa, a luta por direitos e, ainda, por uma educação do campo, é parte constitutiva da luta pela reforma agrária dinamizada no seio dos movimentos e das representações camponesas.

No Ceará, a luta pela terra construída historicamente por sujeitos sociais, muitas vezes geograficamente isolados nos sertões, tem nos dias atuais a resposta de suas ações na conquista de frações do território capitalista que vai para a mão dos camponeses organizados em movimentos e representações camponesas. Assim, não há, portanto, como desconsiderar a importância dos assentamentos rurais no País (Leite et al, 2004). Para esses autores, os assentamentos são vistos como ponto de chegada de um processo de luta pela terra e tornam-se ponto de partida para uma nova condição de vida. Eles estão produzindo um novo perfil produtivo nos municípios, na 
organização social da produção e da família, nas condições de vida e na participação política local e regional.

Nesse processo de luta camponesa, movimentos sociais e representações camponesas trouxeram para o conjunto da sociedade a possibilidade de discutir cultura da igualdade, direito à terra, ao trabalho, à saúde e à educação, entre outros itens. Conforme Arroyo (2004), a organização social, a luta por direitos, trabalho e educação são ações constitutivas de um processo em que o campesinato se constitui sujeito cultural. Por isso, não se deve separar produção de educação, nem produção de escola. A produção na unidade de trabalho familiar na leitura pedagógica dos movimentos sociais e das representações camponesas é mais do que produção. Desse modo, estudar saberes e práticas pedagógicas do campo coloca-nos diante do desafio de dar sentido às palavras a partir do conhecimento específico e das experiências individuais e coletivas construídas na convivência com o povo do campo.

Ao analisar trajetórias camponesas e a relação ensino de Geografia e escola do campo, Oliveira e Silva (2009) revelaram como os saberes referentes à dinâmica da natureza, às formas de uso da terra e aos tipos de solo e vegetação são completamente desconsiderados ou conduzidos por uma lógica pautada no urbano industrial presente nos livros didáticos. Nesse contexto, os autores reafirmaram a preocupação de Oliveira (2008) em contextualizar os conteúdos didáticos com as formas de trabalho e o uso da terra - uso comum, uso individual, uso coletivo e a prática de ajuda mútua, entre outros tipos -, que precisam estar sistematizados de forma criativa e dialógica. Essas formas de trabalho familiar devem ser reconhecidas como ações contextualizadas em espaços e tempos plenos de aprendizagens significativas para a formação humana. O trabalho na unidade de produção e de consumo é parte constitutiva do processo de organização e sistematização dos saberes que alimentam a prática escolar de educadores e educandos.

Os saberes docentes e discentes tem relação direta com a figura da mulher e dos jovens trabalhadores do campo que estão nas frentes de luta dos movimentos sociais. Em suas relações com o mundo natural e social, eles desenvolvem e revelam uma práxis que se dá em várias dimensões: produtiva, política e educativa. São ações, espaços e momentos nos quais os sujeitos sociais estão envolvidos em atividades práticas e elaboram saberes socialmente relevantes para o desenvolvimento de um projeto popular em favor do povo do campo. Na relação conhecimento específico e práticas docente e discente ocorridas com o trabalho na unidade de produção e na escola, a prática social desses sujeitos se revela plena de espacialidade.

No caminho do fortalecimento de uma educação defendida pelos camponeses, a Geografia, como disciplina escolar, tende a assumir uma posição cada vez mais importante na leitura da relação sociedade e natureza no semiárido. Apesar de apresentar pouca relevância curricular tanto para os alunos como para os professores, essa disciplina revelou na leitura sobre a relação sociedade e natureza um potencial a ser discutido e apreendido na prática das escolas de assentamento.

A formação dos professores, o currículo escolar e o material didático que se encontra na escola atual no campo cearense, de uma maneira geral, desconsideram as especificidades da educação do campo e a diversidade da realidade local, realizando, assim, um ensino estagnado, descontextualizado, porém comprometido com a construção da aceitação passiva de novas formas e relações propostas pela política educacional hegemônica. Aqui se coloca uma questão: Qual o sentido da luta a favor de uma política específica de escola do campo?

Fortalecer um projeto alternativo de educação do campo no qual os princípios e a cultura camponesa sejam respeitados; que o papel da escola seja a formação humana (consciência política e prática social); que os trabalhos intelectual e manual estejam presentes na construção de uma gestão participativa, e que a alegria da aprendizagem seja valorizada, são alguns dos pontos que estão sendo desenvolvidos em escolas gestadas pelos sem-terra nos distantes caminhos desse país. 


\section{Escola, geografia e formação contínua de professores}

A escola é o locus por excelência para a formação do professor (Pimenta e Lima, 2004). Com base nessa constatação, fizemos a experiência, na disciplina prática de ensino em Geografia, de acompanhar uma escola pública municipal de ensino fundamental, por meio de visitas e encontros durante oito meses de trabalho. Iniciamos a experiência perguntando aos professores como a universidade poderia contribuir com o fortalecimento da leitura do espaço a partir da relação sociedade e natureza na escola. Logo disseram que o interesse maior da escola era com a prática da alfabetização e leitura, mas que a escola estava aberta para o diálogo na direção da melhoria da prática docente. Recursos didáticos como mapas, jogos e maquetes inexistiam na escola; de fato, os recursos didáticos presentes nas aulas eram o quadro, giz ou pincel e o livro didático. Discutir a relação sociedade e natureza no semiárido nos colocou diante do desafio de desenvolver recursos para estudar o Nordeste e o Ceará, já que os livros didáticos adotados não encerravam esses conteúdos.

Em nossos encontros assumimos a postura inicial de que as professoras já possuíam um saber construído na prática docente e na militância. Apesar de muitas estarem na condição de recém-formadas nos cursos de licenciatura em pedagogia, no magistério da terra ou na pedagogia da terra todas tinham pelo menos 10 anos de experiência com a docência e com a militância no Movimento dos Trabalhadores Rurais Sem Terra (MST). Sempre elaborávamos atividades a partir de suas vivências e do que sabiam, respeitandoas como profissionais e militantes nos diálogos ocorridos. Isso permitiu que se estabelecesse a relação teoria e prática como unidade na diversidade, e a identidade com o projeto popular de escola para o campo pensado pelos movimentos sociais e pelas representações camponesas.

De acordo com Caudau e Lelis(1990) e Mediano(2003), a teoria deve estar atrelada a uma prática real naqueles a quem se dirige, para que seja tomada a consciência da prática ou, pelo menos, dos sentimentos que os animam e que os agradariam ver presentes na prática. No trabalho com as professoras militantes, aprendemos que a teoria só faz sentido se tiver origem na luta por um projeto popular de desenvolvimento do campo.

Assim, a leitura geográfica proposta teve como pressuposto a educação do campo, que se encontra na denominada Pedagogia do Movimento (Caldart, 2004). A discussão inicial dos conceitos de geografia, espaço, sociedade, natureza e semiárido foi desenvolvida a partir do contato com a realidade das comunidades.

Outro ponto importante no acompanhamento da escola do Quieto foi a opção pelo trabalho coletivo. O grupo responsável pela gestão foi composto por oito professoras e a gestão coletiva já era uma prática desenvolvida no grupo das professoras ao longo do processo de construção do movimento de luta pela terra.

considerações:

$$
\text { O trabalho exigiu algumas }
$$

- adotar procedimentos participativos e de diálogo em que o professor seja ouvido, quer pelos colegas, quer pelo animador do grupo. No cotidiano da escola essa prática acaba sendo deixada de lado em meio à sobrecarga de trabalho burocrático. Confrontar ideias e práticas é importante no crescimento profissional.

- criar um clima de proposição com divisão de tarefas e encaminhamentos para assim ir desenvolvendo a confiança entre os participantes. Aqui foram postos ideias, limites e conflitos acerca de questões latentes na relação universidadeescola do campo sobre os quais nunca se havia falado antes. E daí foi fácil analisar a existência de projetos diferenciados para o mundo da escola do campo presente na sociedade.

- ver a importância de adotar uma pedagogia da pergunta (Freire e Faundez, 1985), com esses procedimentos participativos e com esse clima de confiança. Uma pergunta adequada e realizada no momento certo pode trazer boas reflexões sobre nossa prática e avançar no conhecimento. 
Essa abordagem coletiva favorece a construção da autonomia do sujeito e a sua capacidade de análise crítica. Nossas escolas são ainda muito dependentes "das ordens da Secretaria". É, portanto, importante fazer com que o professor, individualmente e como coletivo, seja capaz de se colocar perguntas do tipo: por que se faz assim? Para quê? Para quem? A partir daí, ter coragem de fazer aquilo que parece melhor naquela situação para o coletivo. Evidentemente que a atitude de questionar pode criar problemas para o sistema estabelecido. Mas a ideia do conflito deve estar posta em nossa prática docente.

O Assentamento 25 de Maio está composto de dezoito comunidades, distribuídas em sua área localizada entre os municípios de Madalena, Boa Viagem e Quixeramobim, na depressão sertaneja do sertão central cearense, distante cerca de $150 \mathrm{~km}$ da cidade de Fortaleza e $30 \mathrm{~km}$ do núcleo urbano do município de Madalena. A opção pelo estudo de caso e a escolha da comunidade do Quieto se deu quando fomos informados da proposta pedagógica desenvolvida, com traços da pedagogia da terra, e pela disponibilidade da comunidade-escola para trabalhar com a universidade.

O 25 de Maio foi fruto de uma ocupação organizada pelos camponeses e apoiada pelos sindicatos rurais, pela CPT e pelo MST. De acordo com os camponeses, havia a necessidade de uma organização política capaz de superar a situação de submissão em que se encontravam. O dia 25 de Maio, data marcada para a ocupação organizada pelo MST, denomina hoje a antiga fazenda São Joaquim, de propriedade do Sr. Wicar Parente Pessoa, abrangendo uma área de 22.992,00 hectares, imóvel considerado improdutivo no cumprimento da função social, compreendendo terras exploradas e mata virgem. Nela residiam cinquenta famílias na condição de moradores, inseridos no assentamento e na luta pela reforma agrária. Completados 15 dias da ocupação, foi assinada a emissão de posse da terra em 09 de junho de 1989. Para Azevedo (1992), foi o processo mais rápido até então ocorrido no Estado, tendo sido possível devido à organização do MST, bem como devido à conjuntura política existente em nível estadual e federal em relação ao primeiro Plano Nacional de Reforma Agrária.

O atual prédio da escola no assentamento foi construído a partir da doação de uma cidadã alemã (Jette Joop) - via Cruz Vermelha Brasileira (em parceria com a Prefeitura de Madalena) - de recursos financeiros necessários para a construção da escola na forma como se encontra hoje. Essa atitude contribuiu para que a comunidade a homenageasse, colocando seu nome na placa comemorativa apresentada no descerramento do novo prédio. A escola do Quieto (como é conhecida na localidade), além de ser referência em termos de organização e trabalho no assentamento, apresenta-se em excelente estado de conservação, condição necessária para a prática pedagógica proposta. O prédio tem cerca de dois anos e possui seis salas de aula, uma secretaria, uma cozinha, três banheiros, tendo ao lado um posto de saúde. Antes do prédio atual, a escola funcionava em um antigo galpão da cooperativa que ainda hoje mantém salas de aula e área de estocagem de parte dos produtos produzidos no assentamento.

Isso tudo fez com que todo esse trabalho levasse em consideração a realidade em que a escola - situada em um assentamento rural - está inserida, o que esteve bastante presente nas nossas discussões. Problematizávamos a realidade, discutindo-a, de modo a explicitar a relação que existe entre as práticas escolares e as questões mais amplas da sociedade. Nesses momentos, todos os participantes contribuíam com suas experiências individuais e coletivas, ficando o coordenador com o papel de mediador do debate.

Essa experiência de acompanhar uma escola, trabalhando com o corpo docente, permitiunos chegar a algumas conclusões: a escola é, sem dúvida, o local por excelência para trabalhar a formação dos professores em serviço, pois todos passam pelo mesmo processo, discutem as mesmas questões e se capacitam coletivamente para as transformações necessárias; um processo desses só pode acontecer se a escola tiver uma gestão comprometida com a transformação da realidade social e disposta a acompanhar os professores nessa caminhada; um trabalho dessa natureza leva obrigatoriamente a um repensar nossa prática 
docente, quer seja como professores em formação, quer seja como professores formadores; a escola cresce em credibilidade junto à comunidade, o que pode causar disputas ou fortalecer identidades.

\section{Oficina geográfica com professores em serviço em escolas do campo}

A proposta de trabalhar com oficina geográfica com professores de geografia das escolas do campo foi um desafio que surgiu durante as aulas de prática de ensino em Geografia e em visitas de acompanhamento da pesquisa nos assentamentos rurais. No processo de construção da proposta, o contato inicial com a comunidade do Quieto foi feito através de viagens de reconhecimento das escolas no mundo rural. Após as visitas de campo e a participação em reuniões pedagógicas na secretaria de educação do município de Madalena, propusemo-nos a elaborar uma oficina geográfica com os professores da escola básica, no intuito de fortalecer a leitura da relação sociedade e natureza no semiárido discutido na escola. A proposta foi aceita pelo grupo e encaminhada pelos colegas que viabilizaram o trabalho com o compromisso de que fosse estabelecida uma atividade em conjunto, a ser realizada na escola do Quieto, Assentamento 25 de Maio.

$\mathrm{Na}$ construção do diálogo, muitos dos professores mostraram a necessidade de um instrumental teórico e prático que os ajudasse em sua prática cotidiana. Nesse sentido, as atividades emergiram das necessidades reais do professorado local. Tais atividades foram compostas de aulas expositivas dialogadas com temáticas como a questão da propriedade privada no Nordeste; a luta pela terra e os movimentos sociais; as paisagens geoambientais, e a educação ambiental na prática pedagógica dos professores de Geografia. Foi proposto, também, um trabalho de campo na região do entorno da área do assentamento com o objetivo de se discutir na prática as questões teóricas levantadas.

A mística de abertura dos trabalhos foi iniciada com um tema que enfatizou a educação do campo e a unidade dos trabalhadores da cidade e do campo na luta por uma reforma agrária com escola, terra e dignidade. Para Stedile e Fernandes
(1999), a mística é a força, a energia cotidiana, que tem animado a família sem-terra a continuar na luta, ajudando cada pessoa a enxergar e a manter a utopia coletiva. É o momento em que aquele sentimento, materializado em símbolos, nos faz sentir que não estamos sozinhos, e compreender que os laços que nos unem aos outros lutadores é que nos dão mais força para prosseguir na construção de um projeto coletivo. No MST, a mística tem uma dimensão educativa muito importante: para os militantes mais antigos, ajuda a cultivar os valores e a memória simbólica que os mantém a caminho; para as novas gerações ou para cada sem-terra que entra no movimento, ajuda na disposição pessoal de entrar no processo e a vivenciar as ações de forma mais humana e plena, enfim, é uma espécie de ritual de acolhida, que faz as pessoas se sentirem parte do movimento mesmo antes de conhecer toda a sua dinâmica.

Toda a dimensão da formação humana, da sociabilidade, da integração e do compromisso entre os grupos esteve posta nesse momento de acolhida, considerado por todos repleto de alegrias e intencionalidades. Nessa leitura, concordamos com Maia (2008), quando analisou a mística no MST como um processo educativo. Ao final desse momento e como uma forma de mostrar o orgulho, a organização, e a força do Movimento, os militantes entoaram seu hino e passaram a palavra para nós, professores da UFC.

Após uma breve apresentação do grupo, contextualizamos e colocamos os objetivos da oficina geográfica, demonstrando compromisso e respeito ao movimento de educação do campo proposto pelo MST. A luta pela reforma agrária foi abordada com base em uma leitura dialética marxista sobre o papel da propriedade privada da terra no Nordeste. No debate, foi possível uma ampla discussão sobre a concentração fundiária, a função social da terra e o significado dos movimentos sociais e das representações camponesas na luta pela terra, e a conquista de frações do território.

A leitura sobre as unidades geoambientais e as diferentes paisagens existentes no semiárido brasileiro foi mais um tema abordado. As aulas expositivas dialogadas prezaram por desvelar a especificidade dos diferentes ambientes 
que compõem o território brasileiro e, em especial, exploraram a realidade cearense.

O trabalho de campo foi proposto como um instrumento fundamental na formação dos docentes que trabalham com o ensino de Geografia. A área priorizada para o estudo foi o sertão central. Iniciamos no interior do assentamento discutindo a questão da propriedade privada e a constituição das relações sociais no campo, a partir de evidências que íamos observando, tais como: a diferença no sentido da construção de cercas de proteção e cercas de divisão presente ao longo das propriedades; a utilização da pecuária extensiva como reserva de valor e/ou reserva patrimonial pelos proprietários de terra rentistas, ou seja, aqueles que se apropriam da renda da terra sem nada nela produzir, e as diferentes funções que a terra vai adquirindo a partir do uso social.

Durante o trajeto Madalena > Quixeramobim > Quixadá > Choró > Madalena houve paradas para se fazer a leitura geográfica da diversidade paisagística presente nas subáreas contidas na paisagem dominada pela depressão sertaneja, que se apresenta interrompida esparsamente por maciços residuais (serras cristalinas) e relevos residuais (inselbergs).

A superfície aplainada com suas intercalações de formas residuais, sob forte influência de clima semiárido (regime hídrico concentrado), exibe nessa combinação de componentes naturais a vegetação de caatinga predominantemente arbustiva e às vezes arbórea, típicas da região.

A vulnerabilidade natural dos solos encontrados nessa paisagem - Neossolos Litólicos (rasos e pedregosos), Luvissolos (rasos e argilosos) e Vertissolos (pouco profundos e muito argilosos) - torna-se, ainda, mais sensível à degradação quando submetida às formas de manejo e aos usos a partir de práticas inapropriadas que se efetuam como as queimadas, os plantios em áreas de forte declive ou, ainda, o uso contínuo ou excessivo.

Como consequência, foi possível detectar várias manchas de vegetação com formações secundárias e solos com alterações na composição original, o que revelou um quadro com fortes traços de degradação ambiental.

A região possui solos produtivos do ponto de vista de fertilidade natural, porém a falta de água, entre outras limitações naturais, e principalmente a ausência de orientação técnica têm contribuído para o uso insustentável desses solos, havendo, portanto, uma predisposição ao processo de desertificação na região. As terras do assentamento poderiam ser mais produtivas se de fato houvesse orientação técnica, já que os açudes amenizam a falta de água. Outros temas como educação ambiental, qualidade de vida, moradia e saúde foram intensamente trabalhados com os professores. No processo, uma nova leitura geográfica da diversidade ambiental presente no sertão central cearense foi sendo formada. Em todo o trabalho de campo foram feitas colocações, anotações, e levantados questionamentos sobre as condições socioambientais da área percorrida.

No contato com a realidade, os professores foram tomando ciência do grau de degradação ambiental presente no sertão e da necessidade de se fortalecer uma campanha a favor do não uso de técnicas de degradação da natureza, ou a favor da educação ambiental.

No momento de socialização do trabalho de campo foi fortalecida a importância da relação conhecimento específico curricular e saberes práticos e experiência dos professores na formação docente. Também foram levantados problemas práticos como: o pouco conhecimento por parte dos professores da Geografia como ciência que discute a relação sociedade e natureza na produção do espaço; a necessidade de se propor nas aulas conteúdos relacionados com as formas de trabalho e uso da terra; as lutas sociais e a educação ambiental. Foram propostas construções que pudessem trazer procedimentos e atitudes diferenciadas na relação dos camponeses com o trabalho agrícola, e houve um diálogo no caminho da construção de um relato de campo. Ainda foram distribuídos e indicados textos que contribuíram para o embasamento teórico e para a reflexão da prática docente. Essa atividade procurou atender alguns princípios: trabalhar a Geografia escolar a partir da relação sociedade e natureza; considerar as experiências dos professores/comunidade/alunos como base para o ensino; levar ao conhecimento do professorado diferentes linguagens propostas para a construção da Geografia escolar; elaborar 
práticas metodológicas de ensino que permitam explorar leituras do campo. Foi, portanto, um trabalho dialogado e construído em conjunto com os professores a partir de necessidades presentes em suas práticas docentes.

Desenvolver a pesquisa acadêmica com extensão e formação de professores tem sido uma proposta bastante discutida e desenvolvida no trabalho docente, como podemos vislumbrar em Pontuschka e Oliveira (2002). A prática com os professores da escola do campo foi uma opção construída em conjunto e considerada uma surpresa gratificante por parte dos sujeitos sociais envolvidos. Essa leitura revelou, por um lado, que a relação universidade e escola básica do campo está posta como um desafio em nossa formação; por outro lado, demonstrou que, mesmo com todos os seus limites, a Geografia tem muito a contribuir com a escola do campo, como mostrou as falas a seguir:

O trabalho de vocês foi bom porque a gente vai conhecendo o que nunca conheceu e reconhecendo o que já conhecia. Isso vai ajudando uns e outros a se unir e se entender (líder comunitário, Assentamento 25 de Maio, 2009).

A troca de experiência vivenciada na interação entre os participantes nos possibilitou uma troca de experiência, ou seja, mais aprendizagem sobre o nosso lugar (Professora, Assentamento 25 de Maio, 2009).

Foi muito bom trabalharmos juntos. Fortaleceu bastante possibilitando-nos mais subsídios para intervir de forma consciente junto aos nossos educandos. Espero que outros momentos aconteçam (Professora, Assentamento 25 de Maio, 2009).

Os relatos apresentados pelos professores foram fundamentais para se fazer um encaminhamento na perspectiva da continuidade da construção da relação proposta inicialmente. Encerramos esse momento com satisfação em relação aos objetivos propostos para o período específico, muito embora saibamos que é preciso um trabalho contínuo comprometido com o processo de lutas camponesas. Também, ficou evidente a necessidade do retorno ao assentamento no sentido de produzir instrumentos teóricos e práticos cada vez mais eficazes no trabalho de leitura da relação escola do campo e geografia escolar.

\section{Considerações finais}

O trabalho de pesquisa e extensão na relação escola básica do campo e universidade vaise ampliando e aperfeiçoando por intermédio da prática. Há uma grande diferença no modo como desenvolvemos a oficina com os professores em serviço na escola do campo e os famosos "pacotes educativos" desenvolvidos no interior de gabinetes burocráticos que, muitas vezes, são impostos aos professores. Nossa ação como professores e pesquisadores têm se transformado a partir de nossa prática pedagógica, refletida e analisada em conjunto com outros professores, sujeitos sociais na luta pela terra e pela justiça social. O trabalho de ação-reflexão-ação na prática docente tem permitido o desenvolvimento de educadores que assumem para si o compromisso com a transformação da realidade em que atuam.

A forma dialogada de pensar o conhecimento como um saber em conjunto contribuiu para uma avaliação satisfatória por parte da comunidade e dos corpos docente e discente envolvidos nos trabalhos. Na avaliação final ficou claro que, no início das atividades, o professorado teve dificuldade para entender 0 que exatamente seria desenvolvido na oficina. A própria linguagem foi algo que precisou ser trabalhada para poder ser entendida. Também, optamos por ir (re)construindo as atividades em campo, respeitando a dinâmica da escola, da comunidade e dos professores. Assim, todas as atividades foram refeitas no grupo, apresentadas e novamente modificadas, conforme a necessidade, juntamente com as professoras. A insegurança e a confusão inerentes ao início das atividades foram dando lugar à iniciativa, ao conhecimento, à autonomia e à autoconfiança. A opção por essa forma de trabalho se deu em virtude da liberdade, do compromisso e do respeito dos professores, militantes, pesquisadores e da comunidade com o trabalho desenvolvido na escola.

A experiência desenvolvida desafiounos a produzir, juntamente com os sujeitos sociais que vivenciam o ambiente escolar nas comunidades rurais, um instrumental capaz de fortalecer o 
ensino de Geografia e a proposta pedagogia da terra. Esse encaminhamento tem exigido um repensar sobre nossas práticas docentes, ficando como regra o fato de ser fundamental o trabalho coletivo desenvolvido na trajetória.

Outra constatação que ficou clara foi o fato de que a análise da educação presente no campo brasileiro passa, nos dias atuais, pela leitura de dois projetos inconciliáveis: o projeto oficial e o projeto popular. Um majoritário, feito em nome das relações hegemônicas, que acaba sendo pactuado com a elite, e um popular, defendido pelos movimentos sociais e representações camponesas que atende as necessidades básicas do povo do campo. Assim, a manutenção de diferentes formas de produção e trabalho na terra camponesa, a luta por direitos e, ainda, por uma educação do campo, é parte constitutiva da luta pela reforma agrária dinamizada no seio da sociedade moderna. A pesquisa apresentada se insere dentro das análises teóricas que discutem a educação do campo como um dos elementos que compõem a luta pela terra presente na história do campesinato brasileiro.

Notas

1. Pesquisa financiada pelo CNPq.

\section{Bibliografia}

ABRAMOVAY, Ricardo. Paradigmas do capitalismo agrário em questão. São Paulo - Rio de Janeiro Campinas: Ed. HUCITEC/ANPOCS/UNICAMP, 1992.

ARROYO, Miguel Gozales. e FERNANDES, Bernardo Mançano. A educação básica e o movimento social do campo. Brasília, DF: articulação nacional por uma educação básica do campo,1999. N. 2.

ARROYO, Miguel Gozales. Prefácio. In: CALDART, Roseli Salete. Pedagogia do Movimento Sem Terra. $3^{a}$ Edição. São Paulo: Expressão Popular, 2004.

ARROYO, Miguel Gonzalez. Políticas de formação de educadores(as) do campo. In: Cadernos do Cedes 72. São Paulo: Cortez;Campinas,2007. Pp.157-176.

AZEVEDO, Helena Selma. Identidade resgatada ou nova identidade? 1992. 192f. Tese (Doutorado em Sociologia). Departamento de Sociologia/UFC, Fortaleza, 1992.

BRASIL. Lei de Diretrizes e Bases para Educação Nacional. Lei n. 9.394/96. Brasília,1996.

CALDART, Roseli Salete. Pedagogia do Movimento

Sem Terra. $3^{a}$ Edição. São Paulo: Expressão Popular, 2004.

CALDART, Roseli Salete \& BENJAMIN, César. Projeto popular e escola do campo. Vol. 3. Brasília: Fundação Universidade de Brasília, 2000.
CANDAU, Vera Maria e LELIS, Isabel Alice. A relação teoria-prática na formação do educador. In: CANDAU, Vera (org.) Rumo a uma nova Didática. Petrópolis, RJ: Vozes, 1990. pp.49-63.

CARVALHO, Sandra Gadelha de. Educação do Campo: Pronera, uma política pública em construção. 2006. 296f. Tese (Doutorado em Educação) - Pós-Graduação em Educação da Universidade Federal do Ceará/UFC, Fortaleza, 2006.

FERNANDES, Bernardo M. e MOLINA, M. C. O Campo da Educação do Campo. In: MOLINA, M. C.; JESUS, S. A. de. Educação do campo. Brasília: Ed.UNB, 2004.

FERNANDES, Bernardo M. Os campos da pesquisa em educação do campo. In: MOLINA, M. C. Educação do campo e pesquisa. Brasília: MDA, 2006. Pp. 27-39.

FREIRE, Paulo e Faundez, Antonio. Por uma pedagogia da pergunta. Rio de Janeiro: Paz e Terra, 1985.

FREIRE, Paulo. Pedagogia da autonomia: saberes necessários à prática educativa. São Paulo: Paz e Terra, 1996.

LEITE, Sérgio et al. (orgs.) Impactos dos assentamentos: um estudo sobre o meio rural brasileiro - Brasília: Instituto Interamericano de Cooperação para a agricultura: NEAD; São Paulo: 
UNESP, 2004.

MAIA, Lucíola Andrade. Mística, educação e resistência no Movimento dos Sem-Terra MST. Edições UFC, Fortaleza, 2008.

MARTINS, José de Souza. A educação, entre o balcão e o ensino. In: $\mathbf{O}$ Estado de $\mathbf{S}$. Paulo [Caderno Aliás, A Semana Revista] domingo, 30 de março de 2008, p.J5.

MEDIANO, Zélia. A formação em serviço de professores através de oficinas pedagógicas In: CANDAU, Vera Maria (org.) Magistério construção cotidiana. Petrópolis, RJ: Vozes, $5^{a}$. edição. 2003. p.91-109.

OLIVEIRA, Alexandra Maria de. Saberes camponeses e práticas pedagógicas no campo. In: Mercator, ano 07, número 13, Fortaleza, 2008. p. 47-58.

OLIVEIRA, Alexandra Maria de e SILVA, Edson V. Geografia e Escola do campo: saberes, práticas e resultados. In: Mercator,ano 8, n.16, Fortaleza,2009. p.139-148.

OLIVEIRA, Ariovaldo Umbelino de. A longa marcha do campesinato brasileiro. Revista Estudos Avançados. São Paulo: 15 (43), 2001. Pp. 185 $-206$.
. A geografia agrária e as transformações territoriais recentes no campo brasileiro. In: Novos caminhos da Geografia. São Paulo: Contexto, 1999. p. $63-110$.

PIMENTA, Selma Garrido e LIMA, Ma. Socorro Lucena. Estágio e docência. São Paulo: Cortez, 2004.

PONTUSCHKA, Nídia Nacib e OLIVEIRA, Ariovaldo Umbelino de (Orgs). Geografia em perspectiva. São Paulo: Contexto, 2002.

RAFFestin, Claude. Por uma Geografia do Poder. Ed. Ática, São Paulo, 1993.

SEOANE, José (compilador). Movimientos sociales y conflicto em América Latina. Buenos Aires: Clacso, 2003.

SILVA. José Graziano da. Velhos e novos mitos do rural brasileiro. In: Revista de Estudos Avançados. São Paulo: 15 (43), 2001. p. 37 -50.

STEDILE, João Pedro e FERNANDES, Bernardo Mançano. Brava gente. Fundação Perseu Abramo: São Paulo, 1999. 